\title{
THE CATALYTIC HYDROGENATION OF 2,4-DINITROTOLUENE IN A CONTINUOUS STIRRED THREE-PHASE SLURRY REACTOR WITH AN EVAPORATING SOLVENT
}

\author{
K. R. WESTERTERP, H. J. JANSSEN ${ }^{\dagger}$ and H. J. VAN DER KWAST \\ Chemical Reaction Engineering Laboratories, Faculty of Chemical Engineering. University of Twente, \\ P.O. Box 217, 7500 AE Enschede, The Netherlands
}

(First received 28 February 1991; accepted in revised form 11 November 1991)

\begin{abstract}
An experimental study of the catalytic hydrogenation of 2,4-dinitrotoluene (DNT) in a miniinstallation with a continuously operated stirred three-phase slurry reactor and an evaporating solvent is discussed. Some characteristic properties of the reactor system and the influence of the operating parameters on the performance of the reactor are illustrated. The experimental results are compared with the predictions based on a mathematical model of the reactor system. The results indicate that the assumption of complete saturation with solvent vapors of the gas exit stream out of the reactor does not hold for our small laboratory reactor. It is concluded that, for the mini-installation, the model describes well the operation and further the behavior of the reactor system, and that the model should be fully adequate for large industrial reactors. Further, it was concluded that the kinetics cannot be based on the overall hydrogen conversion determinations alone, and reevaluation of chemisorption constants by analysis of the reactor product composition also is required as soon as a new batch of catalyst is taken into use.
\end{abstract}

\section{INTRODUCTION}

In our laboratories, we are engaged in developing catalytic hydrogenation processes for the finechemicals industry. In this industry, an old, established method is to use an acid and a base metal, such as iron, to generate reactive hydrogen atoms for hydrogenation reactions. In view of the strict government regulations concerning environmental pollution and the high costs of disposal of large, waste streams of metal hydroxides and neutralization salts, catalytic processes are gaining more and more importance for fine chemicals. Furthermore, in general, by the application of catalytic reactions, higher selectivities may be reached and a broader range of synthesis steps, which would not have been possible by conventional techniques, become a vailable.

If complex reactions must be carried out, the selectivity of the desired reaction is a major point of concern and if the reaction also is strongly exothermic, an accurate control of the residence time and of the temperature in the reactor, which usually influence the selectivity strongly, within strict limits is necessary. In a continuously operated reactor the temperature and consequently the course of chemical reaction can be controlled better than in a batch reactor. Heat removal with strongly exothermic reactions requires extensive cooling areas installed in the reactor. Many times, the capacity of the reactor is limited by the cooling area. Further, in fine-chemicals industry, generally, reactor installations must be suitable for multi-product application. As a consequence, high flexibility and good temperature control are

\footnotetext{
'Present address: DSM Research b.v., Process Technology Dept., PT-CP, Geleen, The Netherlands.
}

required. In our reactor concept, we have chosen for the evaporation of the solvent to absorb and remove heat from the reactor, which combines flexibility with accurate temperature control [see Steeman et al. (1961)]. Also, by setting the pressure in the reactor system, the temperature range for a strong cooling by evaporation is set. The vapor is condensed outside the reactor where it is much easier to install the adequate cooling area. If more heat is produced in the reactor more solvent will evaporate, whereas the reactor temperature is hardly affected. In the end, the maximum reactor temperature is limited to a little below the boiling point of the solvent at the pressure the system is set to.

In our laboratory, van Gelder et al. (1990a, b) have studied catalytic hydrogenations of aromatic nitrocompounds in a packed bubble column reactor with an evaporating solvent; they presented mathematical models for this reactor (van Gelder et al., 1990b). Elsewhere (Janssen, 1989), we have described the design of a mini-installation with a continuous stirred three-phase slurry reactor and illustrated the operation of the reactor by the hydrogenation of 2,4,6trinitrotoluene. Details are given of the design and operation of the equipment used, its control and instrumentation, sampling and analytical procedures, testing and calibration, and experimental difficulties met with. Major trouble was caused by crystallization of solutes, and wear and tear in the solid catalyst feed system.

The influences on the performance of the reactor of the different operating parameters, such as the reactor temperature, pressure and residence time, are so complex that it is difficult to argue qualitatively the behavior of the reactor system. Therefore, in order to 
describe the behavior of the reactor, a mathematical model has been derived (Janssen et al., 1992). In this article, we report on an experimental study of the catalytic hydrogenation of 2,4-dinitrotoluene in the mini-installation with continuous stirred slurry reactor and an evaporating solvent, and compare the experimental results with the predictions of the reactor model.

\section{MODEL REACTION}

The hydrogenation of 2,4-dinitrotoluene (DNT) to 2,4-diaminotoluene involves a series of simultaneous and consecutive reactions with several reaction intermediates. A reaction pathway with the relevant stable intermediates is presented in Fig. 1. Note that an ortho-nitro group is converted directly into an aminegroup, whereas a para-nitro group first is converted into a stable hydroxylamine. In Fig. 1, only the 4hydroxylamino-2-nitrotoluene (4-HA-2-NT) is indicated because the 4-hydroxylamino-2-aminotoluene is formed at such low concentrations that it cannot be detected within the accuracy limits of the gas chromatographic analysis used; therefore this compound will be neglected.

The chemistry and kinetics of the hydrogenation of DNT have been discussed in detail by Janssen et al. $(1990 \mathrm{a}, \mathrm{b})$. In these studies, a $5 \% \mathrm{Pd} / \mathrm{C}$ catalyst of Janssen Chimica, Belgium, has been used, whereas for the present study a different catalyst, namely, 5\% $\mathbf{P d} / C$, type E10/R, of Degussa, Germany, has been taken. As generally is the case, the reaction rates with different types of catalysts are not equal. Therefore, in order to recalibrate the parameters in the kinetic model of the hydrogenation reactions over the $\mathrm{E} 10 / \mathrm{R}$ catalyst, a limited number of hydrogenation experiments at 303,328 , and $353 \mathrm{~K}$ and in the pressure range, $100-800 \mathrm{kPa}$ for hydrogen, have been carried out in an automated laboratory batch hydrogenation reactor, according to a standardized procedure (Janssen et al., 1990a). The set of kinetic parameters thus obtained for the Janssen Chimica catalyst has been presented in the previous article (Janssen et al., 1990b). In the hydrogenation experiments with the new catalyst, we determined the hydrogen takeup rates, and on their basis we adjusted, accordingly, the frequency factors of the kinetics constants in the kinetic model of Janssen et al. (1990b).

\section{THE MINI-INSTALLATION}

An outline of the mini-installation is shown in Fig. 2. For a detailed description of the installation, we refer to Janssen (1989). Here, we present a concise description of the equipment.

Hydrogen gas is drawn from a high pressure gas network $\left(\mathrm{HPH}_{2}\right)$, reduced, passed through a thermal mass flow controller and is introduced into the reactor (1) through a sparger just below a Rushton turbine impeller. The DNT solution is drawn from a thermostated storage vessel (16) and is fed into the reactor by means of a membrane pump (18). The feed rate of the solution can be measured accurately with a set of volumetric burettes (17). A concentrated catalyst slurry is drawn from an agitated catalyst supply vessel (14) and introduced into the reactor with a rotating plunger pump (15). The catalyst feed rate can be measured by means of a calibrated gauge glass. The reaction mixture leaving the reactor flows freely through a product cooler into a three-phase separator; the height of the overflow-edge (10) in the separator controls the liquid holdup in the reactor. Solvent vapor and excess hydrogen gas pass through a heated vapor line (3) and enter a condenser/cooler (4). The condensate is separated from the remaining gas (5) and returned to the reactor. The condensate production rate can be determined by closing the valve in the condensate line (6) and collecting the condensate for a certain period of time in the gas-liquid separator, after which it can be tapped and weighed. The effluent gas from the separator passes through an electronic

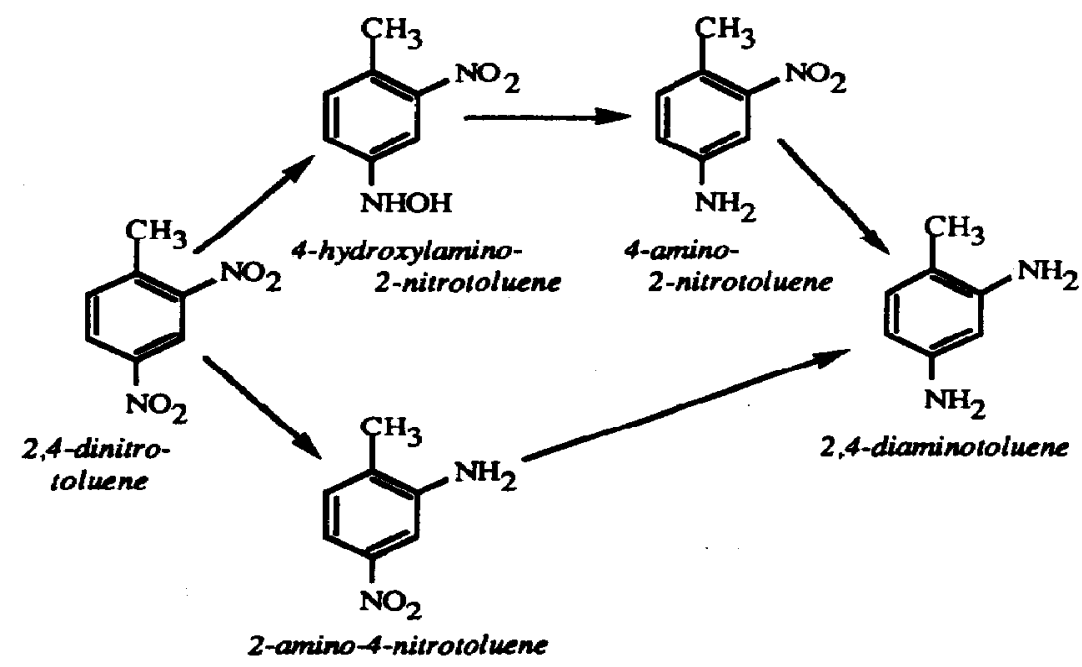

Fig. 1. The reaction pathway for the catalytic hydrogenation of 2,4-dinitrotoluene to 2,4-diaminotoluene. 


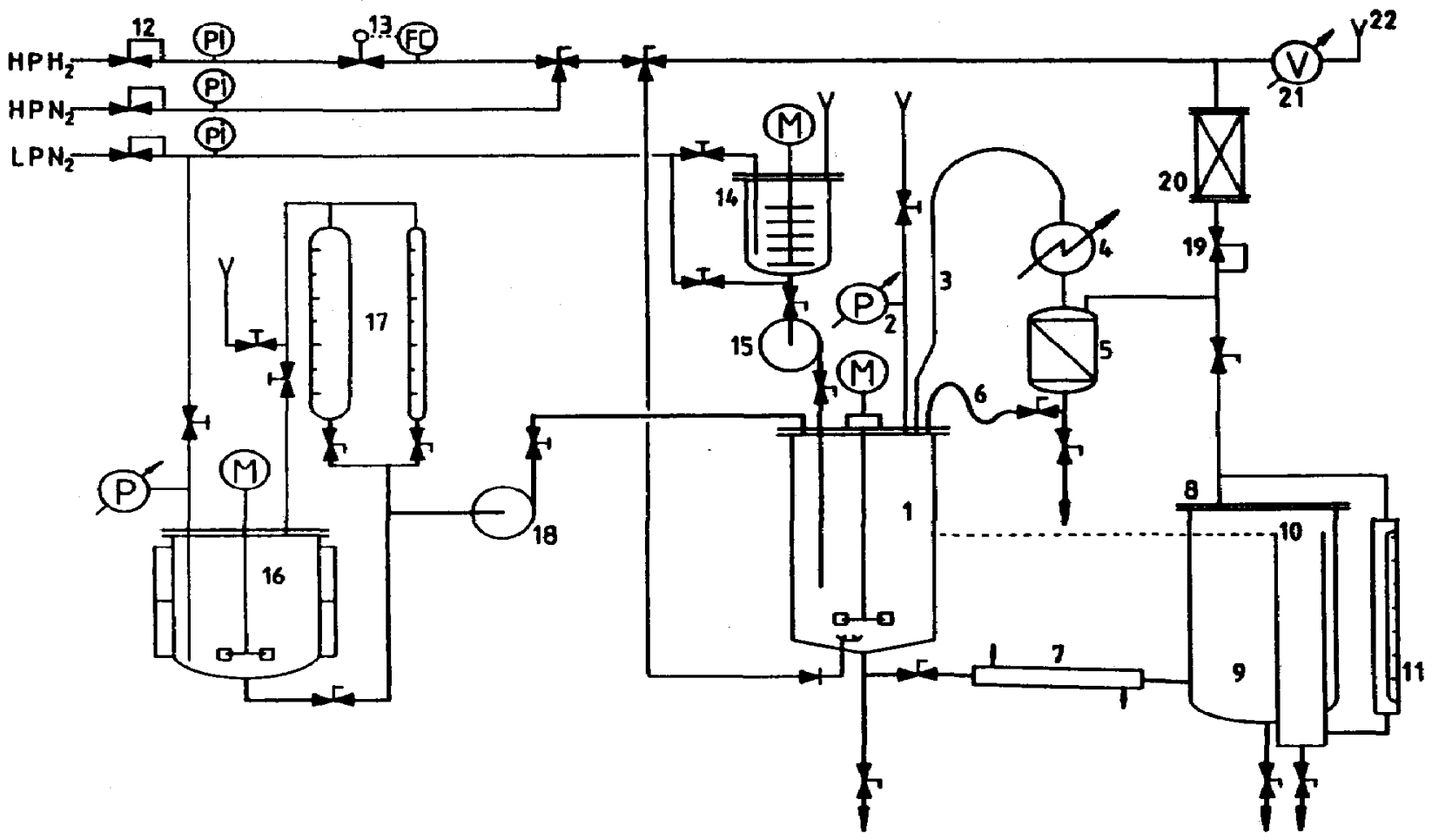

Fig. 2. Schematic flow sheet of the mini-installation; further see text.

back-pressure control valve (19) to control the system pressure and enters a molecular sieve column (20) in which any volatile remaining is adsorbed. Next, the effluent hydrogen gas passes through a calibrated wetgas meter (21) and is released into a ventilation system (22). The temperature of the reactant feed is controlled by electrical heating of the supply line. The vapor line, the top-lid and reactor vessel are heated electrically and covered with thermal insulation shells to reduce heat loss to the surroundings.

\section{EXPERIMENTAL PROCEDURE}

Prior to each experiment, the gas-liquid-solid separator was filled with methanol and the DNT feed line and the vapor line were heated and set to their desired temperatures. The reactor was filled with measured volumes of DNT feed solution and catalyst slurry. Prior to this the reactor had been heated to prevent any undesired crystallization of the DNT in the reactor and to reduce the startup time. Next, the agitator and the hydrogen supply to the reactor were started. After a certain period of time, depending on the consumption of hydrogen measured, feed pumps for the catalyst and the DNT solution were started, and the valve in the product outlet opened. Relevant process and operating parameters were determined at regular time intervals and corrected when needed. To minimize heat losses to the surroundings, temperatures of thermal insulation shells around reactor wall and top-lid were kept approximately $2^{\circ} \mathrm{C}$ below the temperature of the reaction mixture in the reactor. Time to reach the steady-state conditions was in the order of $1.0-1.5 \mathrm{~h}$. Vapor pressure of water was always lower than $3 \%$ of that of the solvent. Total heat balance over the reactor fitted within $5 \%$; this is satisfactory considering the complexity of the installation and the uncertainties in experimental and literature data.

The overall hydrogen conversion in the reactor was calculated according to:

$$
\zeta_{\mathrm{H}_{2} \text { exp }}=\frac{\phi_{\mathrm{H}_{2} \text { in }}-\phi_{\mathrm{H}_{2} \text { out }}}{6 C_{0}\left(\phi_{v . \text { feed }}+\phi_{v \text {. cat }}\right)} \text {. }
$$

Liquid samples were drawn from the reactor by a sampling valve in the product outlet at the bottom of the reactor. The samples have been analyzed with a Varian 3400 gas chromatograph, equipped with a flame ionization detector and a $5 \mathrm{ft}-1 / 8^{\prime \prime}$ Tenax-GC column, $60 \times 80$ mesh. Previous experiments had shown that the samples could not be kept because of the undesired disproportionation reactions of some of the reaction intermediates (Janssen et al., 1990a). Therefore, each sample was analyzed only once, not twice, and, throughout a hydrogenation experiment, as soon as an analytical run of the gas chromatograph was finished a fresh sample was drawn from the reactor and analyzed. In this way, we were able to determine the composition of the reactor product every 10 to $15 \mathrm{~min}$. With the analytical method used, we obtained a direct quantitative analysis of DNT, 24-ANT and DAT. 4-HA-2-NT disproportionated 
instantaneously with injection of the sample, producing 42-ANT and also an unidentified compound with a short retention time. The true concentration of $42-$ ANT in a sample was obtained after correction of the 42-ANT peak for the contribution of disproportionated 4-HA-2-NT; for more details of the calculation method we refer to Janssen et al. (1990a). Overall conversion based on product composition was calculated according to:

$$
\begin{aligned}
\zeta_{\mathrm{DNT}}= & 0.33 c_{4-\mathrm{HA}-2 \mathrm{NT}}+0.50\left(c_{24-\mathrm{ANT}}+c_{42-\mathrm{ANT}}\right) \\
& +c_{\mathrm{DAT}} .
\end{aligned}
$$

An experimental run was terminated by stopping the feed pumps, closing the product outlet simultaneously, and shutting down the hydrogen supply. Then, reactor contents were tapped and weighed to determine the liquid holdup in the reactor. Catalyst concentration in the reactor is calculated from the combined liquid feed rates and the catalyst concentration in the catalyst supply vessel. To check for possible accumulation of the catalyst in the reactor vessel, for some experiments the entire reactor contents were tapped and filtered, and the catalyst collected was washed and weighed after drying. The amount of catalyst found in this way agreed very well with the amounts expected on the basis of feed streams.
A typical experimental run is illustrated in Fig. 3. The installation was automatically heated up during the night, so that in day time several experiments could be executed one after the other. After introduction of the feed streams it took about $1 \mathrm{~h}$ before a stable reactor temperature, reactor pressure and flow rate of the effluent gas were obtained. Operating conditions were changed as given in Table 1 after $2 \mathrm{~h}$ and after $3.5 \mathrm{~h}$, respectively. The entire run lasted just less than $5 \mathrm{~h}$. In Fig. 3, the temperature of the liquid phase in the reactor, $T_{R, l}$, of the reactant feed, $T_{\text {feed }}$, of the gas phase in the reactor, $T_{R, g}$, and of the solvent vapor line, $T_{s v l}$, are plotted vs time. During the experiment 15 liquid samples have been taken for analysis. The moments at which the samples were taken are indicated in Fig. 3 by numbered arrows. We can observe that the stable temperatures of the liquid phase in the reactor are 84,91 and $101^{\circ} \mathrm{C}$, respectively, for the three experiments. Temperature of the gas phase equals the liquid temperature. Initially, the temperature of the feed fluctuated during the first $35 \mathrm{~min}$ of the run; a stationary state was reached about $15 \mathrm{~min}$ after the temperature of the feed had stabilized. The slight differences in the compositions of the liquid samples affirm that the reactor indeed operated at stable conditions after about $50 \mathrm{~min}$. The product distribution in the liquid samples agreed well
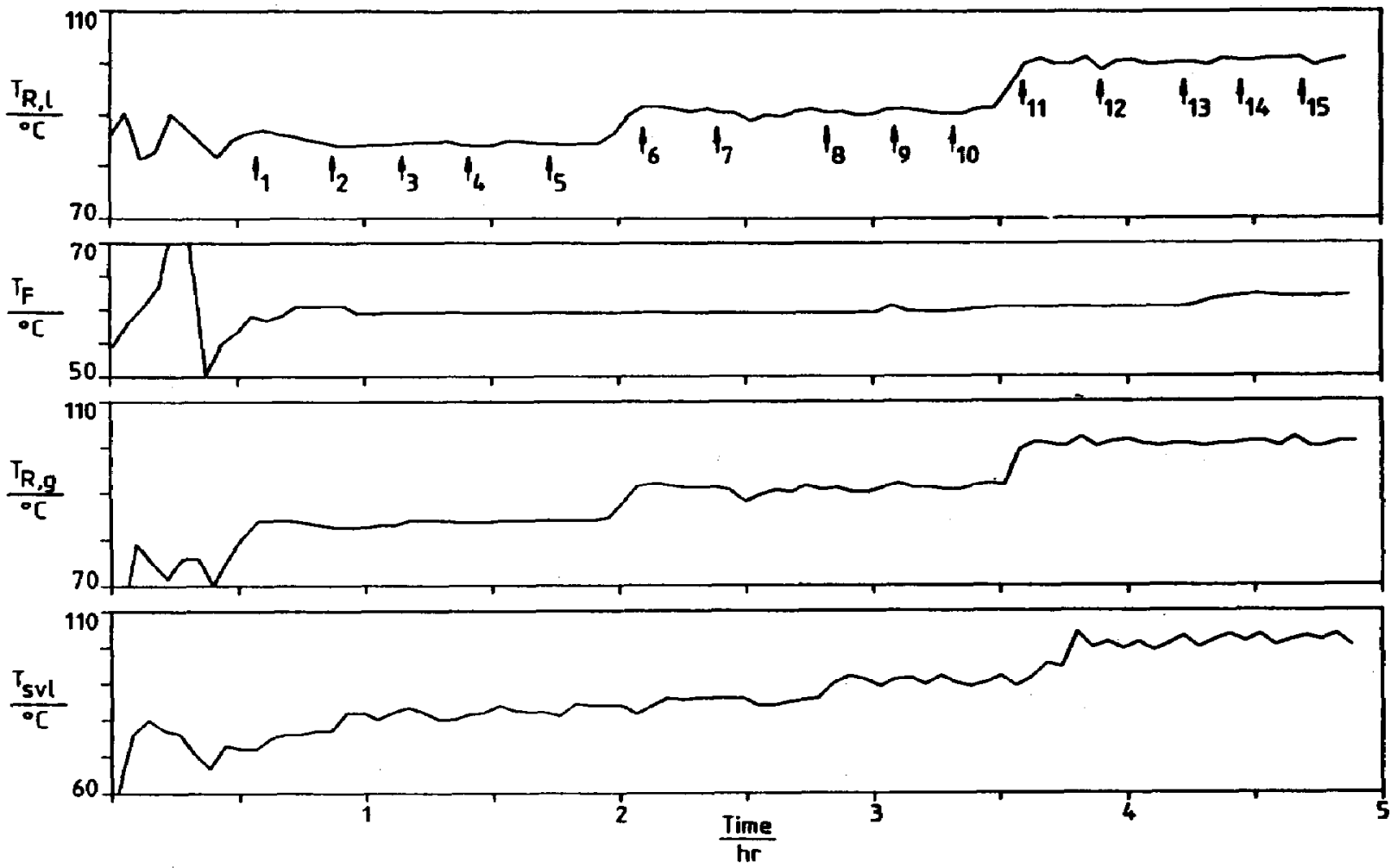

Fig. 3. Liquid-phase temperature, $T_{R, i}$; reactant feed temperature, $T_{\text {feed }} ;$ gas-phase temperature, $T_{R, g}$, and temperature, $T_{\text {svl }}$, of the solvent vapour line during the experiment; arrows indicate the moments of liquid sampling. 
Table 1. Experimental conditions

\begin{tabular}{|c|c|c|c|c|}
\hline \multicolumn{5}{|c|}{ Basic data } \\
\hline $\begin{array}{l}C_{\text {feed }} \\
w_{\text {cal }} \\
\text { Agitation rate }\end{array}$ & $\begin{array}{l}59 \mathrm{~kg} \mathrm{~m}^{-3} \\
35 \mathrm{~kg} \mathrm{~m}^{-3} \\
20 \mathrm{~s}^{-1}\end{array}$ & $\begin{array}{l}T_{\text {feed }} \\
\phi_{v, \text { feed }} \\
V_{R, t}\end{array}$ & $\begin{array}{c}333 \mathrm{~K} \\
2.03 \times 10^{-6} \\
2.0 \times 10^{-3}\end{array}$ & $\begin{array}{l}\mathbf{m}^{3} \mathbf{s}^{-1} \\
\mathbf{m}^{3}\end{array}$ \\
\hline $\begin{array}{l}\text { Experiment } \\
\text { number }\end{array}$ & $\begin{array}{r}\phi_{v} \\
\left(\mathrm{~m}^{3} \mathrm{~s}\right.\end{array}$ & & $\boldsymbol{\alpha}_{\mathbf{H}_{2}}$ & $\underset{(\mathbf{k P a})}{p_{R}}$ \\
\hline $\begin{array}{l}1 \\
2 \\
3\end{array}$ & $\begin{array}{l}180 \times \\
200 \times \\
175 \times\end{array}$ & & $\begin{array}{l}0.98 \\
0.98 \\
1.15\end{array}$ & $\begin{array}{l}250 \\
300 \\
400\end{array}$ \\
\hline
\end{tabular}

with the experimental hydrogen conversion of 0.50 . At this conversion, reaction of 4-HA-2-NT to 42-ANT dominates and very low concentrations of DNT and DAT are expected. The analytical results also illustrate increase of the conversion after start-up.

After $1 \mathrm{~h}$ of operation at a reactor temperature of $84^{\circ} \mathrm{C}$, we changed the operating conditions. Reactor pressure was increased from 250 to $300 \mathrm{kPa}$ and catalyst feed rate was increased by $12 \%$. Compared to the previous situation at a pressure of $250 \mathrm{kPa}$, mole fraction of solvent vapor in the gas phase has become lower. Increased catalyst feed rate will raise the rate of reaction. The system copes with such a disturbance by increasing the temperature in the reactor and conversion. Temperature of the liquid and gas phases stabilized at $91^{\circ} \mathrm{C}$ within $15 \mathrm{~min}$ after the change of experimental conditions. Temperature response of the system was accelerated by electrical heating of top lid and solvent vapor line; temperature set points of these sections were automatically adjusted to the temperature of the liquid phase in the reactor. Increase of hydrogen conversion from 0.50 (at the first steady state) to 0.54 (at the second steady state) is also reflected by the decrease in 4-HA-2-NT concentration in favor of ANT concentration, while not all of 4-HA2-NT has been consumed.

After about one hour, the experimental conditions were changed again. The reactor system reacted in the same way as it did after the first change. The reactor temperature stabilized within $15 \mathrm{~min}$, at $101^{\circ} \mathrm{C}$. The hydrogen conversion of 0.71 is affirmed by the analytical results of the liquid samples, which shows that now a significant amount of DAT is present in the reaction mixture.

\section{EXPERIMENTAL RESULTS}

Physical measurements of the rate of evaporation

It was shown by van Gelder et al. (1990a) that the rate of evaporation of a solvent in a nonreacting isothermal gas-liquid system at equilibrium can be described by the relation $\phi^{\prime}=P^{\prime} /\left(1-P^{\prime}\right)$, where the relative evaporation rate is given by $\phi^{\prime}=\phi_{\text {ev }} / \phi_{0}$, and the relative vapor pressure by $P^{\prime}=p_{S} / p_{R}$. In the model of van Gelder $\phi_{\mathrm{ev}}$ is the stream of the solvent carried away, out of the system by the inert gas feed stream $\phi_{0}$, leaving the reactor, which is equivalent to the stream $\phi_{\mathbf{H}_{2} \text { out }}$ of nonconverted hydrogen gas in the effluent gas.

In order to verify this model for the mini-installation, evaporation experiments have been carried out under nonreacting conditions. To this end, the reactor was filled with pure methanol and heated to a desired temperature by means of electrical heating jacket, and then the production rate of condensed methanol was measured as a function of temperature, system pressure and hydrogen feed rate. The temperature of the vapor line was set at least $10^{\circ} \mathrm{C}$ higher than the temperature in the reactor to prevent condensation of methanol in the vapor line. The temperature of the top-lid of the reactor was kept as close as possible to the temperature in the reactor. In this way, 84 experiments have been carried out in a temperature range $50-80^{\circ} \mathrm{C}$ and at pressures between 300 and $500 \mathrm{kPa}$. Some typical experimental data are presented in Table 2 . The true rate of evaporation was calculated from the experimental

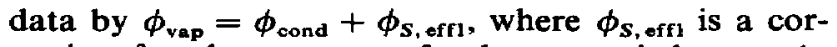
rection for the amount of solvent carried away in the effluent gas. If we assume that the phases are at equilibrium in the gas-liquid separator, then $\phi_{S \text {, eff }}$ $=\phi_{\mathrm{H}_{2} \text { out }} \boldsymbol{P}_{\boldsymbol{S}_{\mathrm{G}-\mathrm{L}}} / \boldsymbol{P}_{\mathrm{H}_{\mathrm{G}-\mathrm{L}}}$ holds. A parity plot of $\phi_{\mathrm{vap}} \mathrm{vs}$ $\phi_{\text {ev }}$ is shown in Fig. 4. The results indicate that the simple model for evaporation rate of methanol from the reactor describes the experimental data well, although the values determined experimentally tend to be slightly lower.

\section{Hydrogenation of 2,4-dinitrotoluene}

In a previous article by Janssen et al. (1990a) it has been illustrated that the most important operating parameters to control the behavior of the reactor system are the reactor pressure $p_{R}$, DNT feed temperature $T_{\text {food }}$, a dimensionless residence time $D a$, given by

$$
D a=\frac{k_{R} \theta_{\mathrm{H}} C_{c \mathrm{at}} V_{R, 1}}{C_{0}\left(\phi_{v, \text { feed }}+\phi_{v, \text { cat }}\right)}
$$

and a dimensionless hydrogen feed parameter $\boldsymbol{\alpha}_{\mathrm{H}_{2}}$ 
K. R. Westerterp et al.

Table 2. Typical experimental data and calculated results for evaporation measurements

\begin{tabular}{|c|c|c|c|c|c|c|c|}
\hline \multicolumn{4}{|c|}{ Experimental } & \multicolumn{4}{|c|}{ Calculated } \\
\hline$\underset{(\mathbf{k P a})}{p_{R}}$ & $\begin{array}{c}T_{R} \\
\left({ }^{\circ} \mathbf{C}\right)\end{array}$ & $\underset{(\mathrm{mol} / \mathrm{min})}{\phi_{\mathrm{H}_{2}, \text { out }}}$ & $\underset{(\mathrm{mol} / \mathrm{min})}{\phi_{\text {cond }}}$ & $\underset{(\mathrm{mol} / \mathrm{min})}{\phi_{\mathrm{ev}}}$ & $\underset{(\mathrm{mol} / \mathrm{min})}{\left.\phi_{\mathrm{s}}\right)}$ & $\underset{(\mathrm{mol} / \mathrm{min})}{\phi_{\text {vep }}}$ & $\phi_{\mathrm{vep}} / \phi_{\mathrm{ev}}$ \\
\hline $\begin{array}{l}305 \\
410 \\
520\end{array}$ & $\begin{array}{l}51.0 \\
52.0 \\
50.0\end{array}$ & $\begin{array}{l}0.136 \\
0.106 \\
0.085\end{array}$ & $\begin{array}{l}0.025 \\
0.014 \\
0.008\end{array}$ & $\begin{array}{l}0.031 \\
0.018 \\
0.010\end{array}$ & $\begin{array}{l}0.007 \\
0.004 \\
0.002\end{array}$ & $\begin{array}{l}0.032 \\
0.018 \\
0.012\end{array}$ & $\begin{array}{l}1.03 \\
1.00 \\
1.06\end{array}$ \\
\hline $\begin{array}{l}310 \\
410 \\
520\end{array}$ & $\begin{array}{l}61.0 \\
60.5 \\
60.5\end{array}$ & $\begin{array}{l}0.067 \\
0.133 \\
0.092\end{array}$ & $\begin{array}{l}0.025 \\
0.032 \\
0.016\end{array}$ & $\begin{array}{l}0.026 \\
0.034 \\
0.018\end{array}$ & $\begin{array}{l}0.003 \\
0.005 \\
0.003\end{array}$ & $\begin{array}{l}0.028 \\
0.037 \\
0.019\end{array}$ & $\begin{array}{l}1.11 \\
1.08 \\
1.03\end{array}$ \\
\hline $\begin{array}{l}305 \\
411 \\
519\end{array}$ & $\begin{array}{l}67.0 \\
64.5 \\
67.0\end{array}$ & $\begin{array}{l}0.091 \\
0.113 \\
0.136\end{array}$ & $\begin{array}{l}0.041 \\
0.032 \\
0.023\end{array}$ & $\begin{array}{l}0.051 \\
0.036 \\
0.036\end{array}$ & $\begin{array}{l}0.004 \\
0.004 \\
0.004\end{array}$ & $\begin{array}{l}0.045 \\
0.036 \\
0.027\end{array}$ & $\begin{array}{l}0.89 \\
1.01 \\
0.75\end{array}$ \\
\hline $\begin{array}{l}305 \\
410 \\
510\end{array}$ & $\begin{array}{l}70.5 \\
70.0 \\
70.0\end{array}$ & $\begin{array}{l}0.067 \\
0.093 \\
0.111\end{array}$ & $\begin{array}{l}0.045 \\
0.038 \\
0.031\end{array}$ & $\begin{array}{l}0.047 \\
0.040 \\
0.035\end{array}$ & $\begin{array}{l}0.003 \\
0.003 \\
0.003\end{array}$ & $\begin{array}{l}0.048 \\
0.041 \\
0.034\end{array}$ & $\begin{array}{l}1.02 \\
1.03 \\
0.96\end{array}$ \\
\hline $\begin{array}{l}302 \\
406 \\
510\end{array}$ & $\begin{array}{l}81.5 \\
81.0 \\
80.0\end{array}$ & $\begin{array}{l}0.067 \\
0.136 \\
0.066\end{array}$ & $\begin{array}{l}0.093 \\
0.106 \\
0.035\end{array}$ & $\begin{array}{l}0.113 \\
0.115 \\
0.036\end{array}$ & $\begin{array}{l}0.003 \\
0.005 \\
0.002\end{array}$ & $\begin{array}{l}0.096 \\
0.111 \\
0.037\end{array}$ & $\begin{array}{l}0.86 \\
0.97 \\
1.03\end{array}$ \\
\hline
\end{tabular}

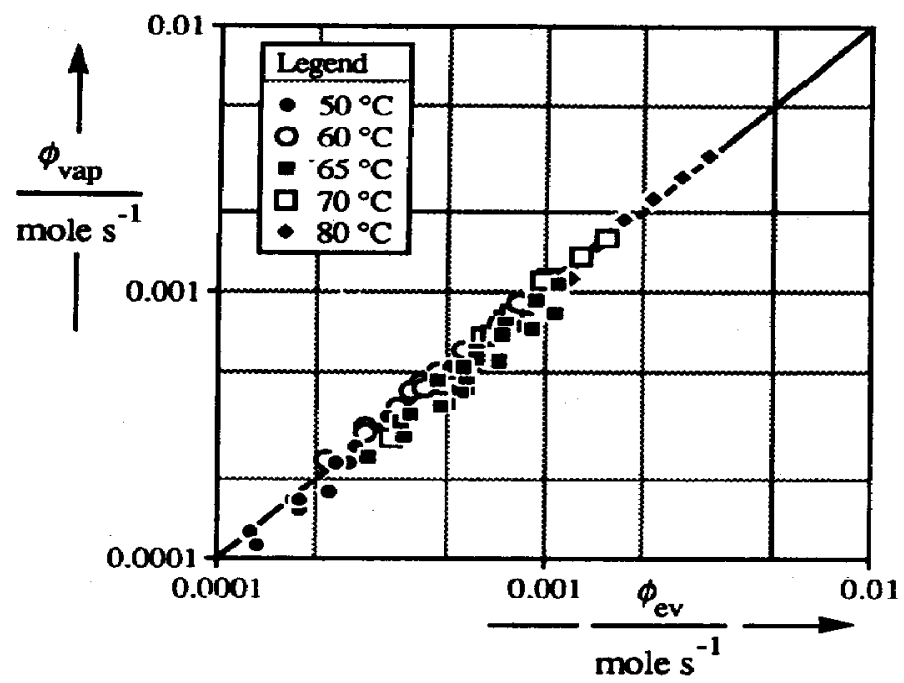

Fig. 4. Parity plot of the measured evaporation rate vs the rate calculated on the basis of solvent vapour pressure and inert gas flow rate.

given by

$$
\alpha_{\mathrm{H}_{2}}=\frac{\phi_{\mathrm{H}_{2} \text { in }}}{6 C_{\mathrm{o}}\left(\phi_{v, \text { feed }}+\phi_{v, \text { cal }}\right)}
$$

which is the ratio of the amount of hydrogen actually fed into the reactor over the amount required for a complete conversion of DNT into DAT. In eq. (3), $k_{R}$ is a kinetic rate constant and $\theta_{\mathrm{H}}$ is the fractional surface coverage of the catalyst with hydrogen, both at a given reference temperature and pressure [see Janssen et al. (1990a)].

Here, we present the experimental results of 16 hydrogenation experiments in the mini-installation, for which the conditions and data are summarized in Table 3. Because the storage tank for the DNT solu- tion was kept at atmospheric pressure, temperature of the feed solution was limited to $60^{\circ} \mathrm{C}$. For all the experiments, the feed temperature was set in the range $40-60^{\circ} \mathrm{C}$. This allowed a DNT concentration in the feed only of 40 to $60 \mathrm{~kg} \mathrm{~m}^{-3}$ to avoid the risk of clogging of the feed line and the membrane pump by crystallization of DNT. To allow for reasonable rates of solvent evaporation, the reactor was operated at moderate pressures, around $300 \mathrm{kPa}$, which resulted in a reactor temperature range, $60-80^{\circ} \mathrm{C}$.

The infuence of some operating parameters

The influence of reactant feed rate, $\phi_{v, \mathrm{feed}}$, is illustrated by exps 9 and 10: if compared to exp. 9, for exp. 10 a lower reactant feed rate results in a higher 
residence time of the reaction mixture in the reactor and consequently, the reactor operates at a higher conversion and heat production rate $H P R$, and at a higher steady-state temperature. The same behavior can be observed by comparing exps 14 and 13 . For the low feed rates of exps 4 and 5, a steady state could not be achieved and the reactor temperature remained drifting throughout the experimental run. The influence of the catalyst feed rate, $\phi_{v, \text { cal }}$, is illustrated in exps 15 and 16 , where in exp. 16 a higher reactor temperature and conversion are reached. These experiments illustrate the effect of Damköhler number $\mathrm{Da}$ on the performance of the reactor system. The hydrogen takeup increases with higher $D a$ numbers. There is a limit to this observation. If the reactor is operated at a constant pressure, with an increasing temperature the partial pressure of hydrogen will decrease because of the increasing partial pressure of the solvent in the reactor. At a certain temperature, the rate decreasing effect of a lower hydrogen partial pressure will become more important than the rate increasing effect of temperature on reaction rates. As a consequence, conversion in the reactor passes through a maximum and it drops to 0 as the reactor temperature approaches the boiling point of the solvent. Beyond this maximum, a change of $D a$ which results in an increase of the reactor temperature causes a decrease in conversion.

The influence of the hydrogen feed ratio $\alpha_{\mathrm{H}_{2}}$ is illustrated by exps 7 and 8: in exp. 8, at a lower value of $\alpha_{\mathbf{H}_{2}}$, less solvent vapor is carried away, out of the reactor, and consequently the reactor operates at a higher steady-state temperature. The influence of the reactor pressure $p_{R}$ can be seen by comparing exps 11 and 12 and exps 16 and 14, respectively. For both cases, we can observe that a decrease of reactor pressure causes a decrease of reactor temperature and conversion.

\section{Heat effects}

For 10 selected experiments the relevant heat effects are summarized in Table 4 . The heat production rate, $H P R$, is calculated by $H P R=$ $\phi_{v \text {, feed }} C_{\mathrm{DNT}}\left(-\Delta H_{R}\right) \zeta_{\mathrm{H}_{2} \text { exp. }}$. Values of heat withdrawal rates, $H W R_{\text {ev }}$, on the left-hand side of Table 3 are calculated on the basis of $\phi_{\mathrm{H}_{2} \text { out }}$ with the assumption that the stream of hydrogen which leaves the reactor is fully saturated with methanol. Values of $H W R_{\text {vap }}$ on the right-hand side are based on the stream $\phi_{\text {cond }}$ of condensate actually collected during an experiment and a calculated stream of solvent $\phi_{S \text {, eff }}$ present in the gas which leaves the gas-liquid separator. For both methods of calculation, in Table 4 the contribution of the heating up of the cold feed stream to the total $H W R$ is the same. For more details on definitions of different heat effects, we refer to Janssen et al. (1990a).

If we compare $H P R$ and $H W R_{\text {tot }}$ listed in Table 4 based on $\phi_{\mathrm{H}_{2} \text { oul }}$, we observe that $H P R$ is lower for nearly every experiment. The deficit cannot be explained on the basis of accuracy of experimental temperature and pressure data: the sensitivity of 


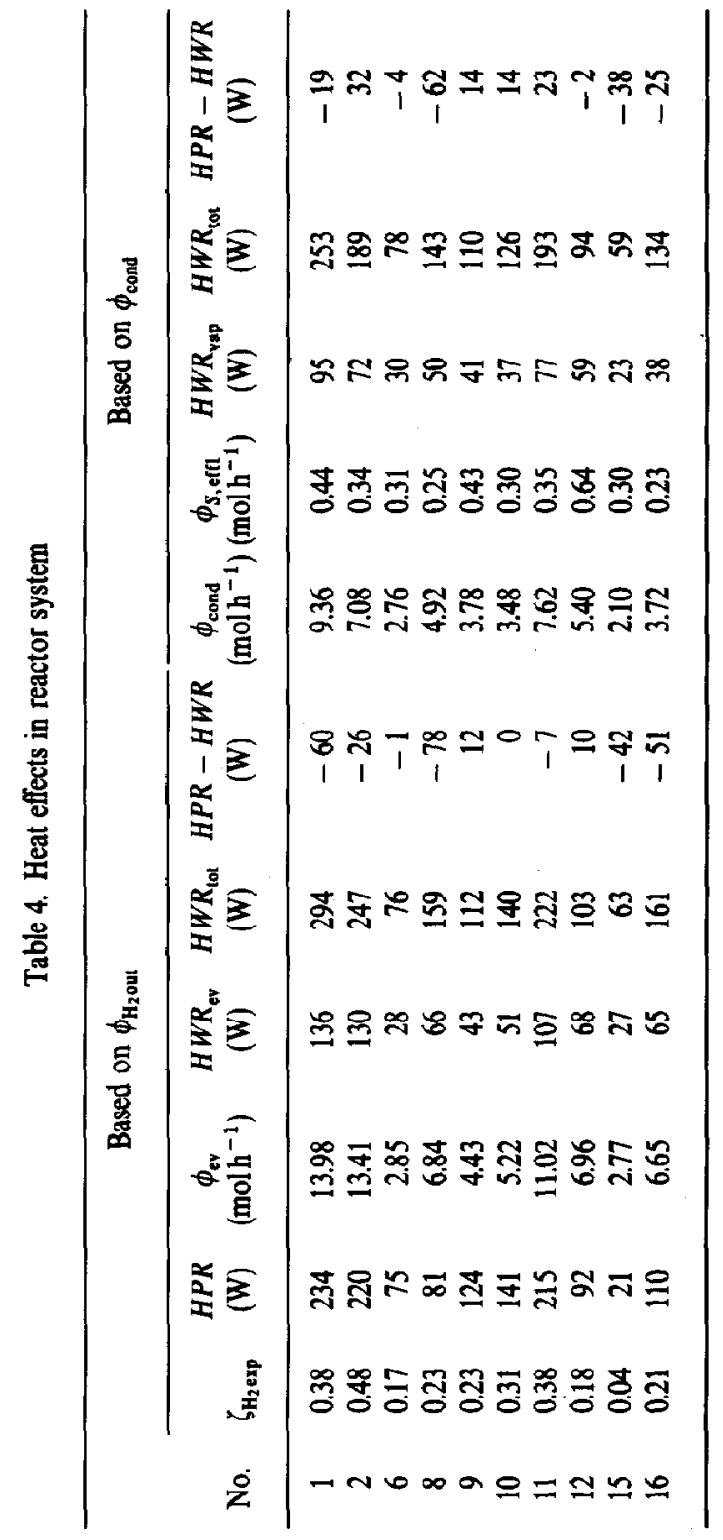

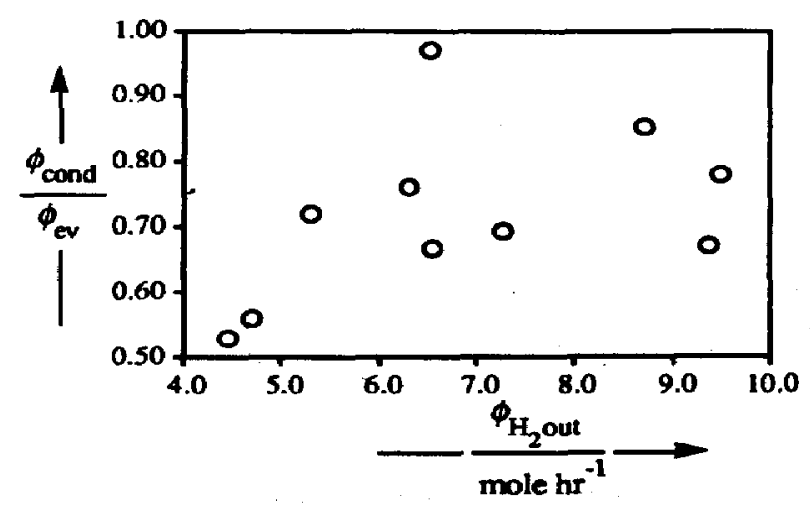

Fig. 5. The ratio $\phi_{\mathrm{cond}} / \phi_{\mathrm{ev}}$ as a function of the effluent stream of hydrogen $\phi_{\mathrm{H}_{2} \text { oul }}$.

$H W R_{e v}$ towards a variation of $1^{\circ} \mathrm{C}$ in the temperature or of $10 \mathrm{kPa}$ in the total reactor pressure is only around 5 to $10 \mathrm{~W}$. On the other hand, if we compare $H P R$ and $H W R_{\text {tot }}$ based on the condensate stream $\phi_{\text {cond }}$, we observe that the average deviation is less than $5 \%$. This still leaves the problem that the amount of condensate collected per unit of time is smaller than the calculated evaporation rate. The same trend was observed during physical measurements of evaporation rate under nonreacting conditions, see Fig. 4. In Fig. 5, the ratio $\phi_{\text {cond }} / \phi_{e v}$ has been plotted as a function of the effluent stream of hydrogen, $\phi_{\mathrm{H}_{2} \text { our }}$. If the discrepancy were caused by incomplete condensation in the cooler/condensor, we would expect the ratio $\phi_{\text {cond }} / \phi_{\mathrm{ev}}$ to be a function of $\phi_{\mathrm{H}_{2} \text { our }}$. The results in Fig. 5 indicate that this is not the case.

We observe from Fig. 5 that under reaction conditions the deviation between experimental and predicted amounts evaporated are large, whereas under nonreacting conditions as in Fig. 4 they almost coincide. It can hardly be expected that reaction under exactly the same conditions of agitation, flow rates, and temperature and pressure would lead to completely different hydrodynamic conditions and so to large differences in mass transfer rates for evaporation. So, some other phenomenon must cause the discrepancies illustrated in Fig. 5.

\section{COMPARISON BETWEEN EXPERIMENTAL RESULTS AND MODEL CALCULATIONS}

The experimental results of the 16 experiments discussed can be compared with predictions of a model of the reactor system (Janssen et al, 1990a). In Fig. 6, reactor temperature predicted has been plotted vs temperature obtained experimentally. The model predicts operating temperatures which are 5 to $10^{\circ} \mathrm{C}$ higher than that found experimentally. Further, the agreement is better at higher reactor temperatures. In Fig. 7 predicted hydrogen conversions are compared with the respective experimental values. Full dots in Fig. 7 represent the conversions at steady-state conditions as predicted by the reactor model; hence both material balance and heat balance equations of 


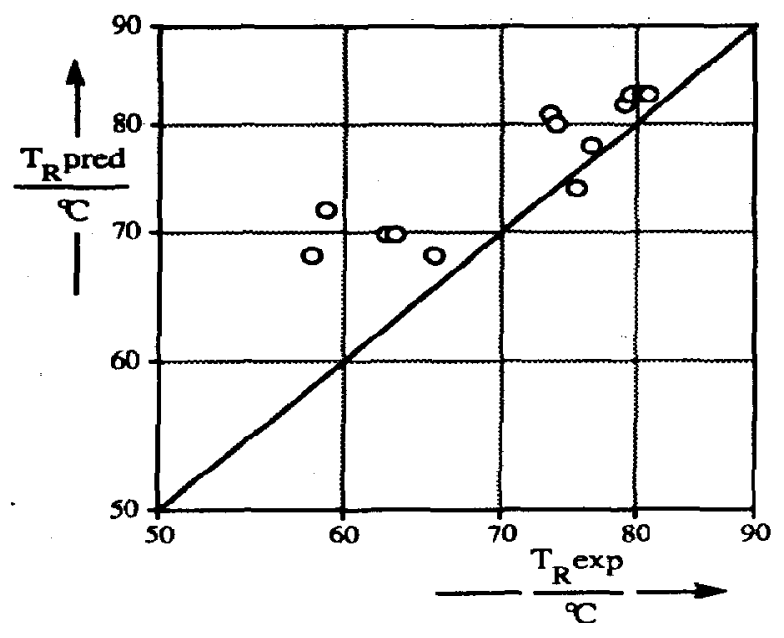

Fig. 6. Experimental reactor temperatures vs temperatures predicted on the basis of the model and the determined kinetics.

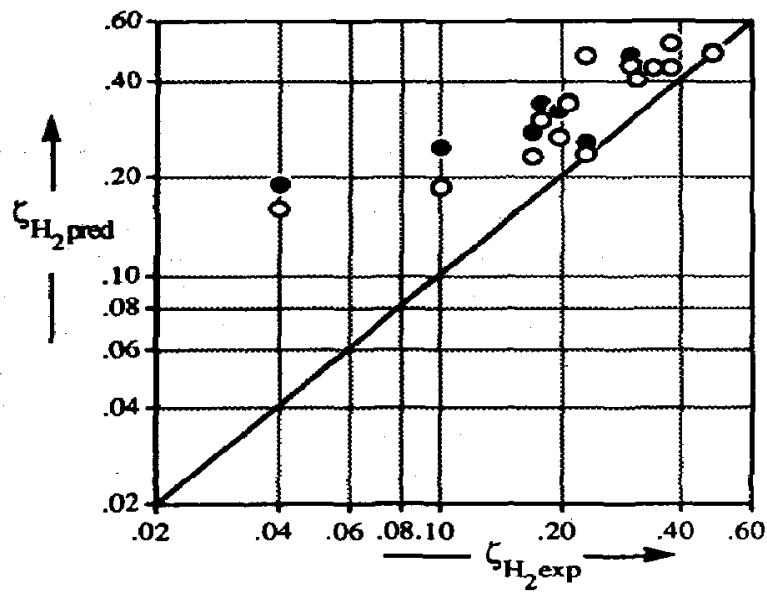

Fig. 7. The experimental hydrogen conversion vs conversion as calculated on the basis of the model and the determined kinetics. (O) Predicted at the steady state; $(O)$ predicted for the steady-state temperature measured.

the model are satisfied. In order to allow for the influence of possible inaccuracies in the description of heat balance terms on steady-state conditions predicted, we also calculated product composition and conversion at the experimentally observed steady-state temperature; note that in this case only the material balance equations of the model are fulfilled and that the heat effects are not balanced. The conversions predicted according to this method are indicated in Fig. 7 by the open circles. We observe the same general trend for the conversions as in Fig. 6 for the reactor temperatures: the predicted conversions are around 0.10 higher than the experimental values and also the agreement is better at higher conversions.

In Fig. 8, we have plotted, as a function of the hydrogen conversion, the relative concentrations of DNT, 24-ANT and DAT in the product stream as

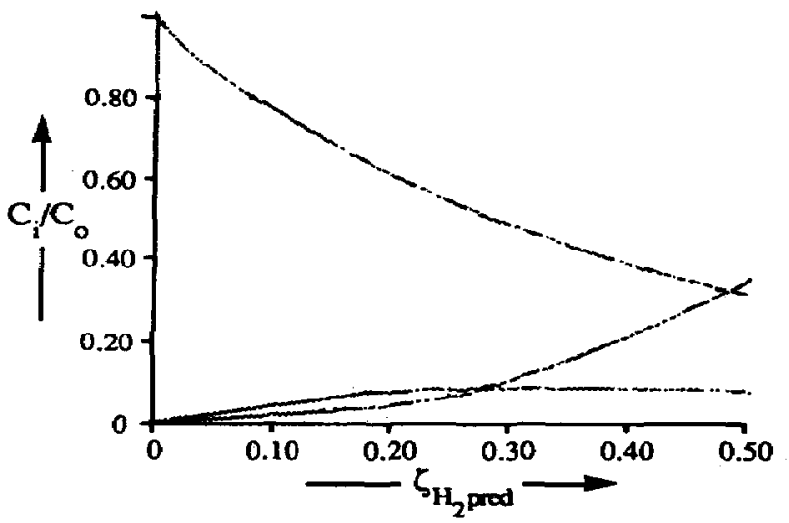

Fig. 8. The relative concentrations of DNT, 24-ANT, and DAT as functions of hydrogen conversion for the steadystate temperature measured on the basis of the determined kinetics.

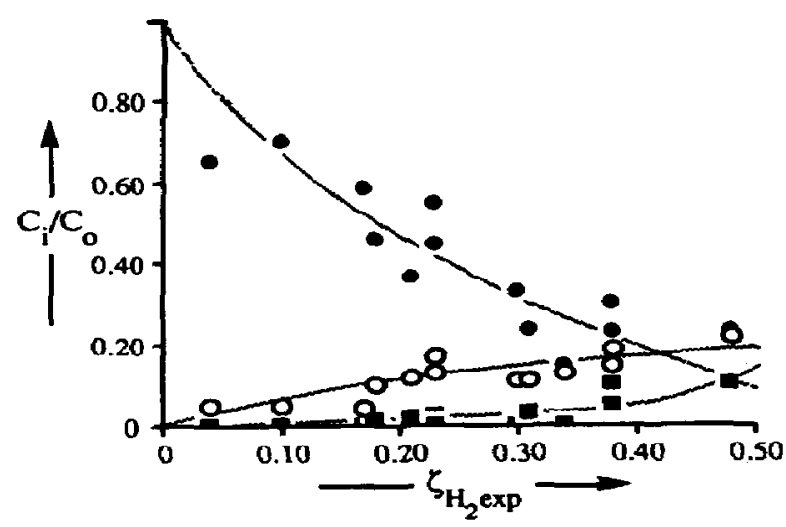

Fig. 9. The relative concentrations of DNT, 24-ANT, and DAT found experimentally as functions of experimental hydrogen conversion.

predicted by the reactor model for the experimentally observed reactor temperatures; note again that the results in Fig. 8 follow from the kinetic model for the case in which the material balance equations are satisfied. In Fig. 9, the same type of plot has been drawn for the experimental data. By plotting experimental data at different temperatures in Fig. 9, we necessarily have a certain spread; nevertheless, we get some interesting results in comparing Figs 8 and 9. We can observe clearly that DNT is adsorbed on the catalyst surface much more strongly than predicted by the kinetic model: experimentally the concentration of DAT in the product stream does not rise before nearly all the DNT has reacted away. Further, we can observe that the experimental concentration of the intermediate product 24 -ANT is about twice as high as that calculated on the basis of the kinetics. The discrepancy between the experimental conversions and conversions predicted by the model, specially in the lower conversion range at lower temperatures now can be explained: the kinetic data used in the model are not adequate. We recall that we readjusted the 
kinetic constants of the catalyst of the new supplier on the basis of fast, automated hydrogen takeup experiments. On the basis of the chemical analyses of the experimentally determined reactor product compositions, we afterwards also readjusted the chemisorption constants. Then, the lines presented in Fig. 9 are obtained and now experimental observation and predictions coincide. We abstain from giving the corrected values here (as they are not of universal value), but conclude that, for each new batch of catalyst, the full range of kinetic experiments must be repeated to obtain new kinetic and chemisorption constants. In another paper by Molga and Westerterp (1992) we have elaborated on this problem.

\section{DISCUSSION AND FINAL REMARKS}

The evaporation rate of the solvent has been measured experimentally under nonreacting conditions as well as during hydrogenation experiments. During the hydrogenation experiments 30 to $50 \%$ of the heat of reaction was absorbed by evaporation of the solvent. If the amount of condensate collected per unit of time is used as a measure for the evaporation rate of the solvent, for most experiments the heat production rate and the heat withdrawal rate are balanced within approximately 10 to $20 \%$. Although this accuracy for a single experiment is poor, over the total of the experiments the average deviation is less than $2.5 \%$.

The experimental limitations of the mini-installation did not allow us to perform experiments at reactor conditions which are favorable to obtain high concentrations of the intermediate product 4-HA-2NT. The analysis of the reactor product stream was not optimal with respect to the two most important intermediate products 4-HA-2-NT and 42-ANT, and has made a quantitative interpretation of the analytical data difficult. Nevertheless, the overall hydrogen conversion $\zeta_{\mathrm{H}_{2} \text { exp }}$ and the conversion calculated from the product composition $\zeta_{\mathrm{DNT}}$ agree fairly well, see Fig. 10. For practical purposes $\zeta_{\mathrm{H}_{2} \exp }$ is preferred to $\zeta_{\text {DNT }}$ because the parameters to calculate $\zeta_{\mathrm{H}_{2} \text { exp }}$, see eq. (1), can be measured accurately.

The discrepancies between the experimental product composition and the composition predicted by the computer model are caused by inadequate kinetic parameters. This flaw in the kinetic model used is the main reason why the conversions and the stable operating temperatures predicted by the computer model are too high. Even though we carefully recalibrated the kinetic parameters for the $E 10 / R$ catalyst by measuring hydrogen conversion rates and compared these with the kinetic data for a $5 \% \mathrm{Pd}$ on active carbon catalyst of Janssen Chimica, Belgium, (see Janssen et al., 1990b), the results obtained demonstrate that we also should have measured the product composition in order to redetermine accurately the chemisorption constants. For the hydrogenation of 2,4-dinitrotoluene at hand, a fresh determination of the exact chemisorption would require at least four months for an experienced laboratory worker. For an

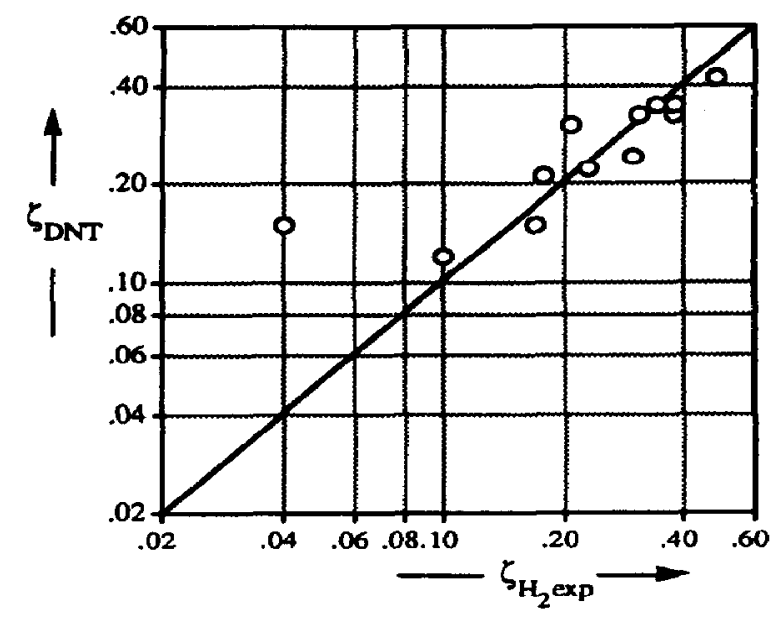

Fig. 10. Comparison of the overall conversion, based on experimental composition of the product stream and hydrogen conversion measured.

industrial situation in which a complex catalytic reaction is carried out, this indicates that we should not underestimate the importance as well as the experimental effort required to determine the kinetic parameters of the reaction system each time the catalyst is changed or a new lot of catalyst is purchased, especially when the reactor model is used for fine-tuning of the selectivity.

Until now, we have focussed our discussion of the experimental results and of the comparison between the predictions by reactor model and the experiments on the heat effects, the evaporation rate of the solvent and on the parameters used in the kinetic model. However, we should also bear in mind the influence on the behavior of the reactor system of the variations and experimental uncertainties in the other operating parameters, like the catalyst concentration in the reactor and the volume of the reaction mixture in the tank. Therefore, we conclude that in general the reactor model describes the behavior of our reactor system well. At the same time, for the relatively small reactor vessel used, a mass transfer term can be incorporated into the model to improve the description of the evaporation rate of the solvent, but we should realize that the relevant mass transfer coefficients and the gas-liquid interfacial areas are not exactly known. However, in a large industrial reactor with high dispersion levels, the residence time of the gas bubbles will be large enough to validate the assumption that the gas phase is fully saturated with solvent vapor. So, for an industrial situation the model is fully adequate.

Acknowledgements-This work has been supported by the Netherlands Foundation for Technical Research, STW, and forms parts of a project initiated by the University of Twente and Andeno b.v., Venlo, Netherlands. The authors also wish to thank A. H. Pleiter, H. J. Vunderink, K. van Bree and W. Leppink for their technical support, and G. Banis and M. L. de Braaf for their assistance in executing the experiments and operating the mini-installation. 


\section{NOTATION}

C liquid phase concentration, mol $\mathrm{m}^{-3}$

$C_{0} \quad$ initial concentration of the reactant in the liquid phase, $\mathrm{mol} \mathrm{m}^{-3}$

$C_{\text {eat }}$ catalyst concentration in the liquid phase, $\mathrm{kg}_{\mathrm{cat}} \mathrm{m}^{-3}$

$c_{j} \quad$ dimensionless concentration of species $j$ $\left(=C_{j} / C_{0}\right)$

$\mathrm{Da} \quad$ Damköhler number, defined by eq. (3)

$H P R$ reduced heat production rate, $W$

$H W R$ reduced heat withdrawal rate, $W$

$\boldsymbol{k}_{\boldsymbol{K}}$

$p$

$P^{\prime}$

$T$

$V_{R, 1}$

$w_{\text {cat }}$

Greek letters

$\alpha_{\mathbf{H}_{2}}$

reaction rate constant at a given reference temperature, mol $\mathrm{kg}_{\text {cat }}^{-1} \mathrm{~s}^{-1}$

pressure, kPa

relative vapor pressure of the solvent, $p^{\prime}$

$\left(=p_{S} / p_{R}\right)$

temperature, $K$

reactor volume, $\mathrm{m}^{3}$

catalyst loading of the catalyst feed stream, $\mathrm{kg} \mathrm{m}^{-3}$

ratio of the amount of hydrogen fed to the reactor over the stoichiometric amount required for the complete conversion of DNT to DAT, defined by eq. (4)

$\Delta H_{R}$

$\zeta_{\mathrm{H}_{2} \exp }$

heat of reaction, $\mathrm{J} \mathrm{mol}^{-1}$

$\zeta_{\text {DNT }}$

overall hydrogen conversion measured, defined by eq. (1) the liquid phase composition, defined by eq. (2)

$\theta_{\mathrm{H}} \quad$ fractional surface coverage of catalyst by hydrogen at a given reference temperature and hydrogen pressure

$\phi_{i} \quad$ molar flow rate of species $i, \mathrm{mols}^{-1}$

$\phi_{v, L} \quad$ total volumetric liquid feed rate, $\mathrm{m}^{3} \mathrm{~s}^{-1}$

$\phi_{v, j} \quad$ volumetric feed rate, $\mathrm{m}^{3} \mathrm{~s}^{-1}(j=$ feed, catalyst)

$\phi_{0} \quad$ inert gas stream flow, $\mathrm{mol} \mathrm{s}^{-1}$

$\phi^{\prime} \quad$ relative evaporation rate, $\left(=\phi_{\mathrm{ev}} / \phi_{0}\right)$

Sub-and superscripts

cat catalyst

cf cold feed cond condensate returned

effl in the effluent gas stream

ev evaporation

feed liquid feed stream of reactant solution

G-L in the gas-liquid separator

in at the inlet

out in the off gas

vap vapor

Abbreviations

$\mathrm{H}, \mathrm{H}_{2}$ hydrogen

$S$ solvent

4-HA-2-NT 4-hydroxylamino-2-nitrotoluene

42-ANT 4-amino-2-nitrotoluene

24-ANT 2-amino-4-nitrotoluene

DAT 2,4-diaminotoluene

DNT 2,4-dinitrotoluene

\section{REFERENCES}

Janssen, H. J., 1989, Selective catalytic hydrogenations in gas-liquid-solid slurry reactions with an evaporating solvent. Ph.D. thesis, Twente University.

Janssen, H. J., Kruithof, A. J., Steghuis, G. J. and Westerterp, K. R., 1990a, Kinetics of the catalytic hydrogenation of 2,4-dinitrotoluene, part I: experiments, reaction scheme and catalyst activity. Ind. Engng Chem. Res., 29, 754-766.

Janssen, H. J., Kruithof, A. J., Steghuis, G. J. and Westerterp, K. R., 1990b, Kinetics of the catalytic hydrogenation of 2,4-dinitrotoluene, part II: modelling of the reaction rates. Ind. Engng Chem. Res., 29, 1822-1829.

Janssen, H. J., Vos, H. J. and Westerterp, K. R., 1992, A mathematical model for multiple hydrogenation reactions in a continuous stirred three-phase slurry reactor with an evaporating solvent. Chem. Enging Sci. 47, 4191-4208.

Molga, E. J. and Westerterp, K. R., 1992, Kinetics of the hydrogenation of 2,4-dinitrotoluene over a palladium on alumina catalyst. Chem. Engng Sci. 47, 1733-1749.

Steeman, J. W. M., Kaarsemaker, S. and Hoftijer, P. J., 1961, A pilot plant study of the oxidation of cyclohexane with air under pressure. Chem. Engng Sci. 14, 139-150.

van Gelder, K. B., Damhof, J. K., Kroijenga, P. J. and Westerterp, K. R., 1990a, Three-phase packed bed reactor with an evaporating solvent-I. Experimental: the hydrogenation of 2,4,6-trinitrotoluene in methanol. Chem. Engng. Sci. 45, 3159-3170.

van Gelder, K. B., Borman, P. C., Weenink, R. E. and Westerterp, K. R., 1990b, Three-phased packed bed reactor with an evaporating solvent-II. Modelling of the reactor. Chem. Engng Sci. 45, 3171-3192. 